\title{
COMMUNICATION SYSTEM FOR THE REMOTE HYBRID POWER SYSTEM IN RAMEA NEWFOUNDLAND
}






\title{
COMMUNICATION SYSTEM FOR THE REMOTE HYBRID POWER SYSTEM IN RAME.A NEWFOUNDLAND
}

\author{
by \\ O Juan Femando Acevedo \\ A thesis submitted to the School of Graduate Studies in partial fulfillment of the \\ requirements for the degree of Master of Engineering.
}

Faculty of Engineering and Applied Science

Memorial University of Newfoundland

May 2011

St. John's

Newfoundland and Labrador 


\begin{abstract}
A reliable communication system is essential for the operation of a remote hybrid power system. Such a system is needed to interconnect the wind turbines, diesel generators, and the bydrogen energy storage unit with a centralized supervisory controller and data acquisition system. For the purpose of this research, we have considered the remote winddiesel-bydrogen bybrid power system currently under development at Ramea, Newfoundland. This thesis illustrates the implementation of a half-duplex collective transmission agreement with low RF transceivers and Power Line Carrier modems which allows the system to have a redundancy network and provide uninterrupted communication between the wind turbines and the main power building. Power line couplers with high pass filters and high frequency amplifiers are also designed and implemented to permit data transmission through high voltage power lines without affecting the performance of the data acquisition system. The researeh also provides the description of wind turbines parameters being measured at Ramea's remote hybrid power solution.
\end{abstract}




\section{ACKNOWLEDGMENTS}

I would like to thank Dr. Tariq Iqbal for his continuous guidance and support, the National Science and Engineering Research Council (NSERC) Wind Energy Strategic Network and Memorial University of Newfoundland for the financial support for this research. I would also like to thank Newfoundland and Labrador Hydro for providing site access and system data. 


\section{TRIBUTE}

I would like to dedicate my work to my parents for their constant and unconditional support, to my family and friends for encouraging me in times of weakness.

"The ultimate challenge is in my mind" 


\section{TABLE OF CONTENTS}

Page

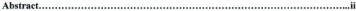

Acknowiedgments................................................................................. iii

Tributc................................................................................................ iv

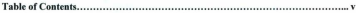

List of Tables......................................................................................... viii

List of Figures................................................................................. ix

List of Abbreviations and Symbols................................................................

List of Appendices.....................................................................................

CHAPTER 1: INTRODUCTION AND LITERATURE REVIEW .....................

1.1 WIND-DIESEL HYBRID POWER SYSTEMS WORLDWIDE $\ldots \ldots \ldots \ldots \ldots \ldots . . . \ldots$

1.1.1 Canada's Wind Power Capacity ................................................ 4

1.2 WIND-HYDROGEN-DIESEL (WHD) POWER SYSTEM OF RAMEA,

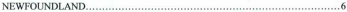

CHAPTER 2: COMMUNICATION METHODS FOR HYBRID POWER

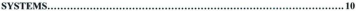

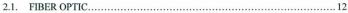


2.1.1 Free Space Optical.

2.2. CONTROLLER AREA NETWORK (CAN) BUS ............................. 14

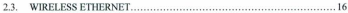

2.3.1 Worldwide Interoperability for Microwave Access (WIMAX) ............... 16

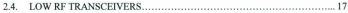

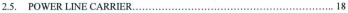

\section{CHAPTER 3: COMMUNICATION SYSTEM FOR RAMEA'S HYBRID POWER}

SYSTEM.............................................................................................. 20

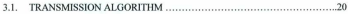

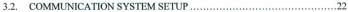

3.2.1. DAST's Microcontroller Pin Configuration ..................................23

3.2.2. Serial-to-Ethernet Adaptor (XPORT XP1001000-03) .........................24

3.2.3. Induetive Coupling Stage ...................................................25

3.2.3.1. High Pass Filter (HPF) ...............................................26

3.2.3.2. High Frequency Amplifier (HFA) ...................................2 28

3.2.3.3. Inductive Coupling Device (ICD) ….............................29

3.3. COMMUNICATION SYSTEM PROTOTYPES ....................................31

3.3.1. Graphic User Interface (GUT) ..............................................32

CHAPTER 4, EXPERIMENTAL RESULTS .........................................35 
4.1. COST-BENEFIT ASSESSMFNT

4.1.1. Benefits...........................,

CHAPTER 5: CONCLUSIONS AND RECOMMENDATIONS .....................40

5.1. FUTURE WORK

BIBLIOGRAPHY AND REFERENCES .............................................45

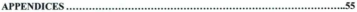




\section{LIST OF TABLES}

Page

Table 1.1. Isolated power system categories......................................................2

Table 1.2.List of Some Wind-Diesel Hybrid Power Systems.................................... 3

Table 1.3. Canada's eurrent wind farm capacity ..............................................5

Table 2.1. Wind Turbine's analog and digital recorded data and sampling time.....11

Table 3.1.DAST's Mierocontroller PIC16F873A Pin Configaration.

Table 4.1.Hardware Cost....................................................................... 37

Table 4.2. Load Consumption. 


\section{LIST OF FIGURES}

Page

Figure 1.1. Curreat Ramea WHD Power Systema...............................................6

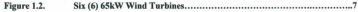

Figure 1.3. Three (3) 100kW Wind Turbines..........................................................8

Figure 2.1. Optical Fiber Cable..........................................................12

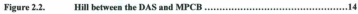

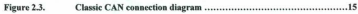

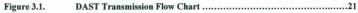

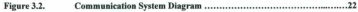

Figure 3.3. Data Acquisition System Transmitter Prototype Setap _...s.sus..........23

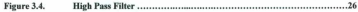

Figure 3.5. 1" Sample of Data Signal ................................................................27

Figure 3.6. $\quad 2^{\text {st }}$ Sample of Data Signal ...........................................................28

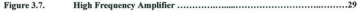

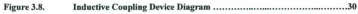

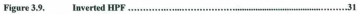

Figare 3,10, Communication System Protetypes ...............................................32

Figare 3.11. Graphic User Interface ..............................................................33

Figure 4.1. Mierocantrodler's Algorithm XPORT initialization + Buffer ...............36

Figure 4.2. ICD \& HPF + HF A Signal ...................................................... 37 


\section{LIST OF ABBREVIATIONS AND SYMBOLS}

AC: Altemate Current

BPL: Broadband over Powerl ines

CAN: Controller Area Network

DAS: Data Acquisition System

DAST: Data Acquisition System Transmitter

DSL: Digital Subscriber Line

EMF: ElectroMagnetic Field

FHSS: Frequency Hopping Spread Spectrum

FSK: Frequency Shifting Keying

FSO: Free Space Optical

GUI: Graphic User Interface

HFA: High Frequency Amplifier

HPF: High Pass Filter

ICD: Inductive Coupling Device

ISM: Industrial Scientific Medical

ISO: International Organization for Standardization

L.AN: Local Area Network

MIMO: Multiple Input Multiple Output

MPCB: Main Power Control Building

MPCBR: Main Power Control Building Receiver 
PLC: Power Line Carrier

RC: Resistor Condenser

RF: Radio Frequency

SCADA: Supervisory Control And Data Acquisition

TCP/IP: Transmission Control Protocol/Internet Protocol

USART: Universal Synchronous/Asynchronous Receiver/Transmitter

USB: Universal Serial Bus

UTP: Unshielded Twisted Pair

WHD: Wind Hydrogen Diesel

Wi-Fi: Wireless Fidelity

WIMAX: Worldwide Interoperability for Microwave Access 


\section{LIST OF APPENDICES}

Page

APPENDIX A. Ramea Wind-Hydrogen-Diesel Project, Realistic Point Count EMS Group - St. John's 55

APPENDIX B. Mierocontroller (DAS) source code 67

APPENDIX C. Gaphic User Interface source code 70

APPENDIX D. Components' datasheets used for this project 73

APPENDIX E. Data Acquisition System Transmitter Sehematic 85 


\section{CHAPTER 1: INTRODUCTION AND LITERATURE REVIEW}

Isolated power systems on ruml communities have been diesel dependent for decades not only to maintain residents' power demands but because of topography challenges they are unable to connect to main power grids. Nevertheless, fossil fuels' continuous cost growth and carbon emissions have made rural power plants shifted from diesel to a combination of renewable energy technology and diesel engines. Having evolved into hybrid power systems, energy grid's control system demands a constant and reliable communication not only to monitoe and control selected carbon free sources of energy but to maintain a balanced distribution on power demand.

\subsection{WIND-DIESEL HYBRID POWER SYSTEMS WORLDWIDE}

Renewable energy systems ean be a sustainable energy source guaranteeing reliability, sustainability, and affordability, but because of their natural characteristics they often have an intermittent energy source which requires complex techniques for optimal utilization. As a counter measure to potential power outages, bybrid power systems provide a higher level of stability with a combination of several carbon-free energy sources like wind or solar and non-renewable sources like diesel or natural gas. Remote power system categories are shown in Table 1.1. 
Table 1.1. Isolated power system categories [1]

\begin{tabular}{|c|c|}
\hline Installed Power (MW) & Category \\
\hline 40.001 & Micro System \\
\hline $0.001-0.1$ & Village Power System \\
\hline $0.1-10$ & Island Power System \\
\hline$>10$ & Large Interconnected System \\
\hline
\end{tabular}

Implementation of these hybrid systems has spread worldwide, countries like Australia, Canada, China, Greece, Norway, UK, USA and others, are increasingly growing their hybrid solutions in order to address global challenges such as carbon emission crisis, fuel flexibility, power efficiency, and economic growth among others. T, Ackerman [1] analyzes the history of hybrid power systems, their categories depending on power eapacity, and illustrates a list of hybrid power systems installed in Sal, Cape Verde; Mindele, Cape Verde; Dachen Island, China; Kythnos, Greece; Lemnos, Greece.

Table 1.2 shows a selection of some wind-diesel solutions installed around the globe, the technical data was retrieved from several references such as Meridian Energy [2], a report containing technical information about Ross Island, Antarctica hybrid energy system. S. Bennett [3] shows a chronological expose of Ross Island's (Antaretica) Wind Energy project progress report up to Dec 2009. The Renewable Energy Alaska Project reports [4]-[5] illustrate technical data about hybrid power projects in Summit station (Greenland), Kotzebue Alaska (USA), Guantanamo (Cuba), Ross Island (Antartica), St. Paul Alaska (USA), Coral Bay (Australia). The National Renewable Energy Labotatory 
[6] presents power capacity information and wind penetration data of the hybrid power system in Mawson, Antarctica. J. Zimmerman [7] and D. Clarke's [8] research has information about isolated renewable energy/diesel systems installed in Bremer Bay, Cocos Island, Denham, Esperance, Hopetoun, Graciosa, Flores, Rottnest, and Ross Istand in Australia. P. Lundsager et al. [9] reports technical information about hybrid power systems installed in: Sal and Mindelo (Cape Verde), La Desirade (Guadeloupe), Marsabit (Kenya), Cape Clear Island and Rathlin Island (Irland), Froya (Norway).

Table 1.2. List of Some Wind-Diesel Hybrid Power Systems

\begin{tabular}{|c|c|c|c|c|c|c|}
\hline $\begin{array}{c}\text { Coentry of } \\
\text { Region }\end{array}$ & Site & $\begin{array}{l}\text { Diesel } \\
\text { Power } \\
\text { (MW) }\end{array}$ & $\begin{array}{l}\text { Wind } \\
\text { Power } \\
(\mathrm{MW})\end{array}$ & $\begin{array}{l}\text { Avg, } \\
\text { Load } \\
\text { (MW) }\end{array}$ & Commissiened & $\begin{array}{l}\text { Inst. Wind } \\
\text { Penetratbon }\end{array}$ \\
\hline Antarctica & Mawson & 0.48 & 0.6 & 0.53 & 2002 & $34 \%$ (avg) \\
\hline Antarctiea & Ross lsland & 3 & 0.99 & 1.73 & 2010 & $70 \%$ \\
\hline Australia & Bremer Bay & 125 & 0.6 & & 2005 & $280 \% 6$ \\
\hline Australia & Cocos Island & 1.28 & 0.08 & & 2005 & $15 \%$ (avg) \\
\hline Australia & Conal Bay & 224 & 0.825 & & 2007 & $290 \%$ \\
\hline Australia & Denham & 1.6 & 1.2 & & 1998 & $250 \%$ \\
\hline Awstralia & Esperance & 14.5 & 5.6 & & 2003 & $>22 \%$ \\
\hline Ausinalia & Hepetoun & 256 & 1.2 & & 2004 & $290 \%$ \\
\hline Australia & Graciosa & 32 & 0.8 & & & $60 \%$ (avg) \\
\hline Australia & Flores & 4 & 0.6 & & & $250 \%$ \\
\hline Ausiralia & Rotinest & 1.3 & 0.6 & & 2006 & $37 \%$ (avg) \\
\hline Canada & Rames & $2 \pi$ & 0.69 & 0.7 & 2004 & $10 \%$ (avg) \\
\hline Cupe Verde & Sal & 282 & 0.6 & 0.56 & & $14 \%$ (avg) \\
\hline Cape Verde & Mindeio & 112 & 0.9 & 1.9 & & $14 \%$ (ave) \\
\hline China & Dachen Islined & 10.4 & 0.185 & & & $15 \%$ (avg) \\
\hline Cuba & Guantanamo & 228 & 3.8 & 12.5 & 2005 & $25 \%$ \\
\hline Grueces & Kythoos Lsland & 2774 & 0.315 & & & \\
\hline Greece & Lemnos island & 10.4 & 1.14 & & & \\
\hline Greenland & Summit & 02 & 0.06 & & & $16 \%$ \\
\hline Gundeloupe & La Desinde & 0.88 & 0.14 & & & $40 \%$ \\
\hline Kenya & Marsabit & 0.3 & 0.15 & & & $46 \%$ (avp) \\
\hline Norway & Fraya & 0.65 & 0.055 & & & $100 \%$ \\
\hline Ireland & $\begin{array}{l}\text { Cape Clear } \\
\text { Island }\end{array}$ & 0.072 & 0.06 & & & $70 \%$ \\
\hline
\end{tabular}




\begin{tabular}{|c|c|c|c|c|c|c|}
\hline $\begin{array}{c}\text { Country or } \\
\text { Regien }\end{array}$ & Sute & $\begin{array}{c}\text { Diesel } \\
\text { Power } \\
\text { (MW) }\end{array}$ & $\begin{array}{c}\text { Wind } \\
\text { Power } \\
\text { (MW) }\end{array}$ & $\begin{array}{c}\text { Avg. } \\
\text { Load } \\
\text { (MW) }\end{array}$ & Commissioned & $\begin{array}{c}\text { Inst. Wind } \\
\text { Pcaetration }\end{array}$ \\
\hline Ireland & Rathlin lsland & 0.26 & 0.99 & & & $100 \%$ \\
\hline USA & $\begin{array}{c}\text { SL. Paul, } \\
\text { Alaska }\end{array}$ & 0.3 & 0.22 & 0.12 & 1999 & $68.5 \%$ (avg) \\
\hline USA & $\begin{array}{c}\text { Kotrebue, } \\
\text { Alaska }\end{array}$ & 11 & 1.14 & 1.37 & & $50 \%$ \\
\hline
\end{tabular}

\subsubsection{Canada's Wind Power Capacity}

Although Canada has made a remarkable effort on expanding its national wind power capacity as seen in Table 1.3, there has been little progress with hybrid power systems development. According to J. Macgillivray [10] and the news reports [11]-[13] the Toktoyaktuk Wind-Diesel project will save 88,000 liters of diesel per year and will offset 247 tones of emissions year long.

According to the research done by T. M. Weis and A. Ilinca in 2007 [14] there have been several low-penetration wind-diesel systems installed across remote Canadian communities like Big Trout Lake (ON), Cambridge Bay (Nunavut), Ellesmere Island (Nuanvut), Fort Severn (ON), lgloolik (NT), Iqaluit (Nunavut), Kasabonika Lake (ON), Kugkluktuk (Nuanvut), Kuujuaq (PQ), Omingmaktok (NT), Sachs Harbour (NT), Rankin Inlet (Nunavut) and Winisk (ON), but only Cambridge Bay and Kuujuaq hybrid power systems where operational for 8 years, the rest had a maximum life span of 2 years,

Other initiatives like PEI's Energy Corporation [15] or B. Saulnier and R. Gagnon [16] are new Canadian developments on hybrid power systems. Projects like Nalcor Energy "Wind-Hydrogen-Diesel (WHD) Power System" in Ramea NL, Northern Wind 
Tuktoyaktuk's project, PEI Wind-Hydrogen Village and Quaqtaq's studies are some of the major research contributions to the few Canadian national efforts to provide rural communities with efficient and cleaner sources of energy in order to reduce carbon emissions as a counter measure to global warming and fossil fael economic challenges.

Technical data from Table 1.3 was retrieved from the Canadian Wind Energy Association (CANWEA) [17] [18] studies; the feports show graphs and tables explaining province's wind installed capacity and the Canadian wind energy projects with a signed power purchase agreement and/or already under construction/construction plan in place as of Aug. 24, 2010.

Table 1.3. Canada's current wind farm eapacity

\begin{tabular}{|c|c|c|}
\hline Provinee & $\begin{array}{c}\text { Installed } \\
\text { Capacity } \\
\text { (MW) }\end{array}$ & $\begin{array}{c}\text { Planaed / Inder } \\
\text { Constructios } \\
\text { (MW) }\end{array}$ \\
\hline Alberta & 884 & 1039.6 \\
\hline British Columbia & 103.5 & 711.2 \\
\hline Manisobs & 104 & 138 \\
\hline New Brinswick & 249 & 163.5 \\
\hline Newfoundland and Labrador & 54.7 & \\
\hline Nova Scotia & 214 & 185.55 \\
\hline Ontario & 1.447 & 4032.1 \\
\hline Prince Edward lsland & 164 & 10 \\
\hline Quebec & 663 & 2361 \\
\hline Saskaichewan & 171.2 & 54.75 \\
\hline Yukcon & 0.81 & \\
\hline TOTAL & 4055.21 & $\mathbf{8 6 9 5 . 7}$ \\
\hline & & \\
\hline
\end{tabular}




\subsection{WIND-HYDROGEN-DIESEL (WHD) POWER SYSTEM OF RAMEA, NEWFOUNDLAND}

Located six (6) kilometers South-West of Newfoundland, Ramea is an island community of 600 residents, its Hybrid Power System, shown in Figure 1.1, has a 2.775MW diesel plant consisting of three $925 \mathrm{~kW}$ diesel generators and six $65 \mathrm{~kW}$ wind turbines located North-West of the island added to the system by Frontier Power Systems (hillpi/hmw. frontierpower.com).

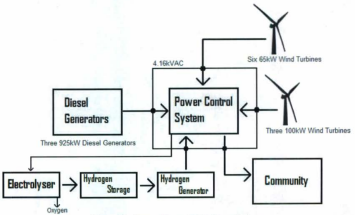

Figure 1.L. Current Rames WHD Power System

According to "Ramea Wind-Hydrogen Diesel Project" 2007 progress report done by Newfoundland Hydro (httpi/lwww.nllh.nl.ca) (a Naloor Energy company), the development of the hybrid power project was undertaken by Nalcor Energy 
(htlps/hww. alicorenergy.com), they upgraded it in 2009 with three new $100 \mathrm{~kW}$ wind turbines sited north of the Island and a Hydrogen facility currently under development [19]. Their power infrastructure combines wind, bydrogen, and diesel generators in order reduce the isolated community dependence on diesel and replace it with energy generation from a renewable resource.

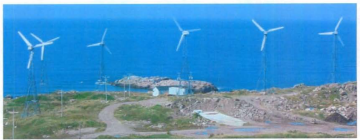

Figere 1.2. Six (6) 65kW Wind Turbines

In September of 2004, Newfoundland Hydro began purchasing wind energy from Frontier Power's wind turbines (WindMatic WM15S, see Figure 1.2) which can have a combined wind penetration of $10 \%$ and offsets approximately 750 tones of emissions annually. The new three $100 \mathrm{~kW}$ wind turbines installed by Nalcor Energy were positioned $130 \mathrm{~m}, 200 \mathrm{~m}$, and 270m (see Figure 1.3) from the Main Power Control Building (MPCB). Naleor Energy's winter 2010 "Ramea Report" mentions that the new wind turbines were commissioned in December 2009 and generated energy on the Ramea grid for the first time on May 8, 2010 [20]. 


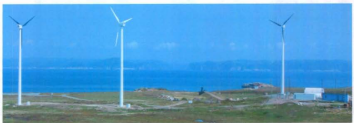

Figzure 1.3. Three (3) 100kW Wind Turbines

With Frontier Power's wind turbines Data Acquisition System (DAS) located $1.6 \mathrm{~km}$ of the Main Power Control Building, the only remote connection currently installed is a wireless link between the DAS and the MPCB by the use of two Cirronet HN-210D transceivers. Unfortunately they are constantly having communication failures, especially during winter season. According to the HN-210 datasheet, its functional frequency is $2.4 \mathrm{GHz}$ ISM band which allows them to operate in the free-license electromagnetic spectrum [21]. The problem relies in transmitting under hazardous weather conditions like snow storms, rain, hail, or a combination of all three, limiting remote supervision and control; a $2.4 \mathrm{GHz}$ transmission is vulnerable to atmospheric attenuation. A reliable and low cost communication solution must be engineered in order to have a trustworthy control of Ramea's Hybrid Power System.

A communication system prototype for the remote WHD hybrid power system currently under development at Ramea, Newfoundland is presented in this document which motivation and focal points involve a cost-effective solution to maintain reliabie and uninterrupted data transmission throughout the power grid, no modifieation on current 
power infrastructure, a combination of different communication methods working in sync for superior transmission stability, and comparison of commonly preferred techniques which will highlight the advantages and usefulness of this project. The proposed system is based on bybrid transmission between a wireless connection and data communication through existing power lines.

In chapter 2, hybrid power systems' communication methods are evaluated in order to have a broad analysis of the engineering involve in this thesis. In chapters 3 and 4 , system prototype features and advantages are introduced, engineering design is explain in detail, and finally lab results and cost-effective solutions are studied for evaluation purposes. Conclusions and recommendations are discussed in chapter 5 for possible future development of the project. 


\section{CHAPTER 2: COMMUNICATION METHODS FOR HYBRID POWER SYSTEMS}

Hybrid power solutions are always demanding trustworthy communications between renewable and non-renewable power systems to facilitate supervision and control of carbon free sources of energy and maintain a balanced distribution on power demand. In order to accomplish a constant and reliable communication link, numerous technologies need to be evaluated based on performance under any weather condition, transmission security, dedicated physical layer dependence, cost-effective solution, bandwidth capabilities, among others. The study will focus on technologies like Fiber Optic, FSO, CAN Bus, Wi-Fi, WIMAX, Low RF links, and PLC.

Table 2.1 shows a sample of analog \& digital parameters measured to run proper diagnostics on wind turbine performance, statistical analysis, historical data record, updates on weather changes, remote control, dynamic warnings, and other features needed for the hybrid powee system's Supervisory Control And Data Acquisition (SCADA). A suitable and reliable physical layer of communication is indeed needed for un-interrupted remote recording of these parameters, A. L. Percin in 2000 studied methods like Parallel ports, Universal Serial Bus (USB), and Ethernet LAN for "Modular supervisory controller for hybrid power systems" [22]. R. Sebastian, M. Castro, E. Sancristobal, F. Yeves, J. Peire, and J. Quesada in 2002 proposed in their research "Approaching hybrid wind-diesel systems and Controller Area Network" a CAN Bus as a 
suitable implementation for hybrid wind-diesel systems [23]. Ramea's power system communication network relies on Fiber Optic and RF wireless transceivers, but there is no mention (wireless communication excluded) of a non invasive technique that does not require modifying the infrastructure such as Power Line Carrier or PLC which can be adjusted to meet this requirement.

Table 2.1 was sampled from Newfoundland Hydro's "Ramea Wind-Hydrogen-Diesel Project, Realistic Point Count for EMS Group - St. John's" report. They provided the hard copy in February 2009 so please refer to Appendix A for fult scanned table content.

Table 2.1. Wind Turbine's analog and digital recorded data and sampling time

\begin{tabular}{|c|c|c|c|}
\hline WindMatic WMIss & Unit & Point Type & Sean Rate \\
\hline Inverter Power & $\mathrm{kW}$ & Analog & $10 s$ \\
\hline Rotor Speed & RPM & Anabog & $10 \mathrm{~s}$ \\
\hline Inst. Wiad Speed & $\mathrm{m} / \mathrm{s}$ & Analog: & $10 \mathrm{~s}$ \\
\hline Ope Min.Avg Wind Speed & $\mathrm{m} / \mathrm{s}$ & Analog & $10 \mathrm{~s}$ \\
\hline Ten Min Arz Wind Speed & mis & Analog & $10 \mathrm{~s}$ \\
\hline Hours Online & & Analog & 105 \\
\hline Cumulative Energy Production & $\mathrm{kWh}$ & Analog & 105 \\
\hline Breaker Status & Open' Closed & Digital & $10 \mathrm{~s}$ \\
\hline Permission to Operate & Yes/No & Digital & 105 \\
\hline
\end{tabular}




\subsection{FIBER OPTIC}

In recent years, Fiber Optic has become more appropriate for high speed data communication. The use of optic light pulses through the fiber lines instead of electronic pulses makes it unaffected to electromagnetic interferences, and with proper thermoplastic over-coating insulation it can be suitable to transmit under extreme weather conditions as mentioned in 1994 by H. Kirkham et al. [24]. Figure 2.1 below (retrieved from Home Theater Accessories Resource commercial webpage "How Optical Cable Works" [26]) shows the composition of an optical cable, Mary Bellis' article on "The birth of fiber optics" explains that a Fiber optic cables are optic wires inside an outer insulation that transmit digital information using light waves traveling by intemal reflection over longer distances than any other high speed wired form of communication [25].

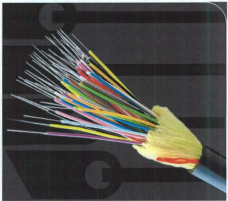

Figure 2.1. Optical Fiber Cable 
Fiber optic networks can handle high speed data transmissions (up to several Gigabytes) and has been used for the communication network of the new three (3) $100 \mathrm{~kW}$ wind turbines at Ramea. Even do the eurrent fiber optic cables connecting these wind turbines to the MPCB allow them to reach Gbps transmissions, Table 2.1 above shows that the parameter scan rate does not require high bandwidth eapability. Inconveniences like elevated costs and installation makes fiber optic not suitable for Ramea's bybrid power system. According to Newfoundland Hydro, CANS19,380.00 was the estimated cost for only the fiber optic cables and considering expanding this network to the $65 \mathrm{~kW}$ wind turbines' DAS will not fulfill the low budget aspiration of this project.

\subsubsection{Free Space Optical}

Emulating a Fiber Optic communication in a wireless environment could be another approach. A. Akbulut, H. Gokhan Ilk, F. Ari in 2005 mention in their study "Design, Availability and Reliability Analysis on an Experimental Outdoor FSO/RF Communication System", that a Free Space Optical (FSO) technology ean provide a $155 \mathrm{Mbps}$ full duplex connection, but the FSO devices have to be carefully installed in specific locations as they need a "Line-of-sight alignment", and data tmansmission is very susceptible when exposed to poor weather conditions [27]. This option is also not suitable for Ramea because of its low performance during poor weather conditions and since line of site transmission is not possible due to a hill between wind turbines' DAS and the diesel plant (Figure 2.2). 


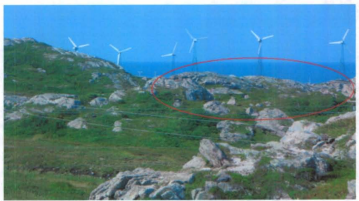

Fizure 2.2. Hill between the DAS and MPCB

\subsection{CONTROLLER AREA NETWORK (CAN) BUS}

In 1986, the German company BOSCH developed CAN initially as a communication protocol for automotive applications. Shortly after, it was standardized in the International Organization for Standardization ISO 11898 \& 11519 allowing the protocol to be used in a wide variety of networking devices including automotive, naval, medical and industrial applications as mentioned in Renesas Electronics Corporation "Introduction to CAN" study on CAN's outline, protocol, features, and standard specifications [28].

For a small overview of this communication method please refer to Renesas Electronics Corponation's "CAN connection diagram" on Figure 2.3 below, the CAN Controller decides the bus level (Dominant or Recessive) by the potential difference between the 
two cables (the "Bus"), connected transmitters send signals to the receiver by altering these levels. If two or more devices transmit at the same time, the CAN Controller will decide which signal pass first depending on their priority starus.

Even though the 2002 study of ${ }^{*}$ Approaching hybrid wind-diesel systems and Controller Area Network" mentions some advantages to the usage of a CAN Bus like switching from eentralized to distributed control and minimum wiring, this communication method still needs a dedicated physical layer, an antagonistic feature to the un-modified power infrastructure attribute of this research. Additionally, the CAN Bus dependence on clock synchronization is an unnecessary feature that can be avoided with other communication technologies.

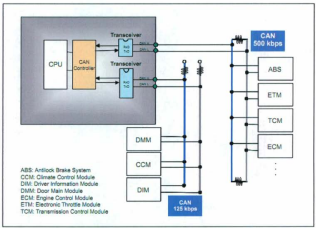

Fugure 23. Classic CAN consection diazram 


\subsection{WIRELESS ETHERNET}

Since the beginning of the $21^{\text {st }}$ century, wireless networks have been exponentially growing and constantly required for faster Ethernet \& Internet access. Cheaper installation expenses and total independency from physical Ethernet ports are the most attractive fearures in wireless communications.

Low budget commercially available wireless Ethemet modem/routers that uses the IEEE $802.11 \mathrm{~g}$ or $802.1 \mathrm{ln}$ standard work in the $2.4,3.6$ and $5 \mathrm{GHz}$ frequency bands and a usual bit rate of 54Mbs (modems that uses IEEE802.11n standard can achieve up to $600 \mathrm{Mbps}$ ), and its outdoor transmission varies from $100 \mathrm{~m}-420 \mathrm{~m}$ without compromising their bandwidth capabilities, Intel Corporation's article on "Helping Define 802.11n and other Wireless LAN Standards" states that increasing the throughput ean be achieved by using the technology referred to as Multiple-Input-Multiple-Output (MIMO) which utilizes multiple signals from an array of antennas across a designated area [29], but this means a bigger investment to purchase signal repeaters. These modems are discarded for this project due to their dependence on present conditions and their limited outdoor communication range.

\subsubsection{Worldwide Interoperability for Microwave Access (WIMAX)}

Another possibility could be the use of WIMAX, a wireless telecommunication technology that uses the IEEE 802.16 standard, provides mobile intemet access, around 40Mbps bandwidth, and operates under licensed spectrum owned by wireless service 
providers. According to Intel Corporation's study on "How WIMAX works", mobile WIMAX base stations over metropolitan size areas can provide wider coverage than WiFi networks (up to two kilometers depending on terrain), and used commonly as a last mile wireless broadband replacement for Digital Subscriber Line (DSL) [30]. Nevertheless, the transmission is outside the unlicensed electromagnetic spectrum so there has to be a contract involved with a WIMAX carrier. Therefore, it would be a costly solution for hybrid power systems.

\subsection{LOW RF TRANSCEIVERS}

Transeeiver is a device that has the capability to transmit and receive within the same circuitry. RF Transceiver uses Radio Frequency modules usually for high speed bps transmission, a wireless approach to LANs, but under extremely hazardous weather conditions like snow or hail storms common in Ramea during winter season, wireless transmission frequency band must be in sub-GHz. From Dr. J. Takei's analysis on "Digital Wireless Communication Basics; Overview of basic concepts", it is conceptualized that RF transceivers employing frequencies close to $900 \mathrm{MHz}$ makes them perfect to transmit even in extremely bad weather conditions as no attenuation and RF wave scattering is generated by snow or rain drops [31].

Even though the bit rate is lower than the Wireless Ethemet modems, they are very appropriate for Ramea's communication system as we conld transmit data packages at low speed (57.6kbs) without affecting DAS performance. This data transfer rate can sustain Ramea's current wind farm remote supervision and control. 


\subsection{POWER LINE CARRIER}

Power Line Carrier (PLC) or Power Line Communication technology incorporates high frequency signals traveling throughout power networks to dedicated PLC receivers distributed among the same complex. Using electric power transmission conductors as communication media will achieve a bidifectional data communication saving resources without installing new dedicated cabling. Applications for this technology include D, D. Bois, Energy Business "Broadband over Powerlines (BPL) in a Nutshell", which provides on-site users with high speed internet access through regular power outlets [32], and "Home Automation" [33] technology that allows house residents to control lights \& appliances remotely using PLC modules such as: NETGEAR [34], X10 [35], LonWorks [36]. INSTEON [37], EHS (European Home Systems) [38], KNX PL. 110 [39], among others.

Above applications focus on domestic use (commonly 120-240VAC power lines) but to successfully transmit data through high voltage cabling ( $1 \mathrm{kVAC}$ ), without damaging microcontrollers or other low voltage devices, there has to be a proper installation of stage circuitry such as: Dedicated PLC modems connected to microcontrollers, a coupling and filtering stage between the modems and high woltage carriers, and a final synchronization process with the high voltage signal. The purpose is to have a bilateral communication between the DAS and the MPCB without modifying the power system infrastructure currently in place at Ramea. 
In order to achieve a constant transmission, a redundant communication network can be accomplished if PLC operates as primary link and low RF transceivers as backup. Using PLC as primary is based on continuous presence of the power line cable, it is usually available the $24 \mathrm{~h}$ of any giving day as it is permanently connected from DAS to the MPCB but if a miscommunication oceurs then the wireless link will become enabled for data transmission. By implementing PLC and low RF transceivers we can achieve a reliable low cost communication system for control and data acquisition of Ramea's hybrid power system.

The rationale to opt for PLC \& Low RF transceivers instead of the others is based on the previous analysis of above technologies. PLC \& Low RF have economically feasible modems, accurate transmission capabilities under any weather condition, embedded wireless transmission encryption, no dedicated physical layer, redundant communication capabilities as a bybrid comm. system, the capability for future expansion to more than a pair of modules with the same type of modems, and bandwidth capabilities necessary for Ramea's WHD power system. Details of proposed communication system are provided in the next fwo chapters. 


\section{CHAPTER 3: COMMUNICATION SYSTEM FOR RAMEA'S HYBRID POWER SYSTEM}

The eommunication system design is based primarily on transmission continuity and reliability, that is why the DAS-MPCB network will have two different types of technologies, the PLC system will be setup as primary and wireless link as backup. Low budget Netgear XE102 PLC modems can accomplish a safe communication with a modified coupling stage that will allow a safe link to the existing high voltage carrier (4.16kVAC). This modems use TCP/P protocol and has LAN compatibility matching the necessary requirements for a remote access and network management from Newfoundland Hydro's coatrol centre in St. John's, NL.

For the wireless link, LaridTech AC4790 transceivers are suitable for Ramea's atypical weather. Its datasheet stipulates a functional frequency variance between $902-928 \mathrm{MHz}$, a serial interface, enhanced interference rejection, an enabled co-located system operation with increased output power and data integrity [40]. Preliminary field testing demonstrated that sucoessful transmission can be achieved at a maximum distance of $2.01 \mathrm{~km}$ under optimal (no rain, hail or snow) weather conditions and no line of sight.

\subsection{TRANSMISSION ALGORITHM}

Figure 3.1 shows the transmission algorithm that the Data Acquisition System Transmitter (DAST) follows. The DAST cmulates receiving data from wind turbine parameters mentioned in Table 2.1 and then they are sent primarily through the PLC; the 
Main Power Control Building Receiver (MPCBR) then replies an acknowledgement signal which finally closes the DAS-MPCB communication loop. Failure to do so, the DAST recognizes this as a communication breakdown and re-transmits the same information through the wireless link and wait for the MPCBR to acknowledge the data. Whenever a new data package is ready for transmission, the DAST will send it again through the PLC and wait for the MPCBR's reply, if the MPCBR fails again the DAST will try to close the communication loop through the wireless link. Please refer to Appendix B for microeontroller's source code.

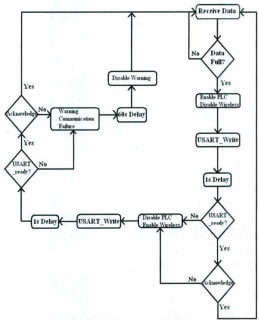

Flgure 3,1. DAST Transmissioe Flow Chart [41] 


\subsection{COMMUNICATION SYSTEM SETUP}

Figure 3.2 illustrates the complete communication system with the two communication prototypes.

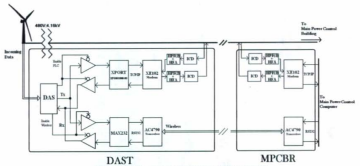

Flzure 3.2. Commenicationa System Diagram $142 \mid$

The microcontroller (PIC16F873A) or DAS serial interface (refer to Appendix E for full DAST schematic) is connected to a gate controlled TTL, buffer (SN74ABT125) setup that allows the DAS to administrate the desired transmission link (see Figure 3.3). While the AC4790 needs RS232 protocol (MAX232ACPE), the PLC modem (Netgear XE102) needs TCP/IP, so a Serial-to-Ethemet adaptor (XPORT XP1001000-03) is used to conneet the buffer setup to the XE102, this enhances the DAS-MPCB link with independent protocols for the two communication carriers. The AC4790 receives the data through RS232, adjust the signal with a FHSS FSK modulation, and sends it to the MPCBR. On the other hand, the Xport adaptor receives the data using the RS232 serial 
interface (CMOS Asynchronous, SV Tolerant), and sends to the XE102 modem using TCP/IP protocol. Please refer to Appendix E for DAST's sehematic diagram, each stage is explained in subsequent sections.

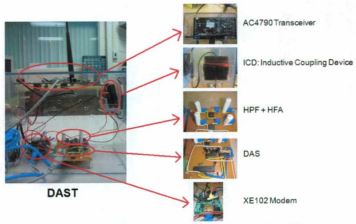

Figare 3.3. Data Acunuisition System Transmitter Prototype Setap [42]

\subsubsection{DAST's Microcontroller Pin Configuration}

Table 3.1 describes the purpose and application for each of the PIC16F873A pins considering the following classification: NC: Not Connected; L: Input; O: Output; TTL: Transistor-Transistor Logie Input/Output; ST: Schmitt Trigger Input/Output; P: Power. 
Table 3.1. DAST's Mierocontroller PIC16F873A Pin Configuration

\begin{tabular}{|c|c|c|c|c|}
\hline Name & Pin $n$ & $\begin{array}{c}\text { Type } \\
\text { (LON) }\end{array}$ & $\begin{array}{l}\text { Buffer } \\
\text { Type }\end{array}$ & Description \\
\hline MCIRVpp & 1 & & & RESET \\
\hline R.AOAN0 & 2 & - & TII. & NC \\
\hline RALANI & 3 & - & TIL. & $N C$ \\
\hline RAZ/ANZVVKEF-AVVKF & 4 & 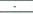 & TIL & $\mathrm{NC}$ \\
\hline RA3/AN3/ VRIF- & 3 & - & TII. & $\mathrm{MC}$ \\
\hline RAATOCKLCIOUT & 6 & - & ST & $\mathrm{NC}$ \\
\hline RAS/AN4SSICZOUT & 7 & 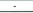 & TTL & $\mathrm{NC}$ \\
\hline Vss & 8 & $\mathrm{P}$ & 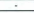 & GND \\
\hline OSCl/CLKI & 9 & 1 & & Crystal oscillator \\
\hline OSC2/CLKO & 10 & $\mathrm{o}$ & & Cnstal oscillator \\
\hline RCOTIOSOTICKI & 11 & - & ST & $\mathrm{NC}$ \\
\hline $\mathrm{RCl} / \mathrm{TIOS} 1 / \mathrm{CCP} 2$ & 12 & 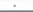 & ST & $\mathrm{NC}$ \\
\hline $\mathrm{RC2} 2 \times \mathrm{CPI}$ & 13 & - & ST & $\mathrm{NC}$ \\
\hline RC3/SCK/SCL & 14 & + & ST & $\mathrm{NC}$ \\
\hline RCA/SDISSDA & 15 & - & ST & $\mathrm{NC}$ \\
\hline RCSSDDO & 16 & - & ST & $N C$ \\
\hline RCETXCK & 17 & 0 & ST & Serial Tx \\
\hline RC7/RXDT & 18 & 1 & ST & Serial $R x$ \\
\hline Vss & 19 & $\mathrm{P}$ & - & GND \\
\hline$V_{D 0}$ & 20 & $\mathbf{P}$ & + & $5 \mathrm{v}$ \\
\hline RBOINT & 21 & 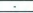 & $\mathrm{TTL} / \mathrm{ST}$ & $\mathrm{NC}$ \\
\hline $\mathrm{RBI}$ & 22 & $\mathrm{O}$ & 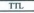 & PCL High frequency buffer control \\
\hline RB2 & 23 & 0 & TTL & Wireiess High frequency buffer control \\
\hline RA3/PGM & 24 & 0 & TTL & LED control - Green \\
\hline RB4 & 25 & 0 & $T T L$ & L.ED control - Rod \\
\hline RBS & 26 & - & TTL & NC \\
\hline RA6/PGC & 27 & - & TTLST & NC \\
\hline RB7FGD & 28 & - & $\mathrm{TTLST}$ & NC \\
\hline
\end{tabular}

\subsubsection{Serial-to-Ethernet Adaptor (XPORT XP1001000-03)}

Lantronix, Inc. "XPort Embedded Device Server" is used to link DAST's PIC16F873A to the XE102, its function is to adjust microcontroller's TTL data to TCP/IP protocol and transmit them to the PCL modem. Even though this device is relatively small $(33,9 \mathrm{~mm}$ long. $16.25 \mathrm{~mm}$ wide, $13.5 \mathrm{~mm}$ tall), it comprises a $4 \mathrm{Mb}$ flash memory, a $25 \mathrm{MHz}$ crystal 
oscillator, circuit reset feature, $5 \mathrm{~V}$ serial interface, embedded UART (compatible with $300-921600$ bps transmissions), Ethernet technology up to $100 \mathrm{Mbps}$, and an external RJ45 jack connected to a UTP cable (See Appendix D for detail technical data) [43].

Once the XPORT is connected to a Local Area Network (L.AN), a fixed IP address is assigned to it using the "Devicelnstaller" software, and finally Telnet or a Hyperterminal application is used for the pos-configuration process (UART setup for example).

The XPORT package comes with an extra tool called "Redirector" which can be used to create virtual ports for easier data access while programming the User Graphic Interface mention in the sabsequent section 3.3 .1 .

\subsubsection{Inductive Coupling Stage}

According to the analyzed powet distribution system at Ramea, the WMISS Wind Turbines generate $480 \mathrm{~V}$ which is then converted to $4160 \mathrm{~V}$ with a step-up transformer. A coupling stage is needed to allow a successful connection between the PLC modems and the $4.16 \mathrm{kV}$ power line. Note in Figure 3.2 that the coupling is performed after the 480:4.16kV step-up transformer in order to avoid transmission instability. V. Krishnan Transformer Bypass Circuit" study on Power Line Communication applications, capacitive and inductive eoupling methods for PLC modules and power line cables, are the baseline for The DAST and MPCBR setup with an active filter (High Pass Filter (HPF), plus High Frequency Amplifier (HFA)) and an Inductive Coupling Deviee (ICD) 
to ensure low frequency signal discrimination and proper signal propagation [44]. Refer to section 3.2.3.1, $2 \& 3$ for full HPF, HFA and ICD analysis. After the MPCBR recognizes the data the acknowledgement signal is sent back through the power line elosing the bilateral communication cycle.

\subsubsection{High Pass Filter (HPF)}

One of the designs for active high pass filters are based on passive HPF followed by an HFA, first order Resistance \& Capacitance ( $R \& C$ or $R C$ ) filters (Figure 3.4) are designed to attenuate low frequency signals including the induced $\mathrm{AC}$ from the $4.16 \mathrm{kVAC}$ plus noise signals remaining only high frequency signals from the XE102 modem.

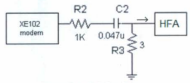

Figure 3.4, High Pass Filter

Measures and analysis from several samples of XE102 output demonstrated that its lowest frequencies are above $5 \mathrm{MHz}$, as an example Figure $3.5 \& 3.6$ shows an instance of the sampled signal. 


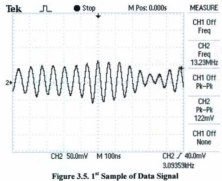

Following high pass filter mathematical formulas found on A. S. Sedra \& K. C. Surith "Microelectronic Cireuits", the $R \& C$ values are based on a passive first order HPF with a -3db gain, which guarantees that low frequency signals are properly discriminated [45].

Cutoff frequency $\left(f_{f}\right)$ of $1 \mathrm{MHz}$ is enough to acquire acceptable results:

Assuming $\omega=\omega_{0}\left(\omega\right.$ : angular frequency; $\omega_{0}$ : cutoff frequency $)$

Where $\omega=2^{*} \pi^{*} f(f:$ frequency $)$

For a first order circuit $\omega_{0}=\frac{1}{R C} \Rightarrow 2 * \pi * f=\frac{1}{R C}$

$f=\frac{1}{(2 * \pi * R \cdot C)}$

Substituting $C=0.47 \mu F$ and $R=3 \Omega$

$$
f=\frac{1}{(2 * \pi * 3 \Omega * 0.047 \mu F)} \approx 1 M H z
$$




\subsubsection{High Frequency Amplifier (HFA)}

After the high frequency signal passes the HPF a percentage is attenuated as seen in Figure 3.6. With the intention of matching the input signal shape while increasing the output, the High Frequency Amplifier seen in Figure 3.7 will correct the attenuation in order to have proper signal propagation by the ICD.

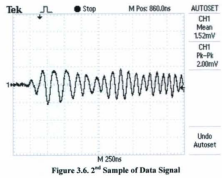

The HFA design is based on the LM6171, a high speed low power low distortion voltage feedback amplifier necessary for circuit requirements (datasheet on Appendix D); operates with $100 \mathrm{MHz}$ bandwidth, a supply voltage range of $\pm 36 \mathrm{~V}$ and $\pm 5 \mathrm{~V}$, and scope gain of 20-200. 


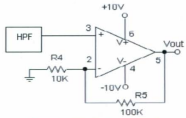

Figure 3.7. High Frequescy Amplifier

\subsubsection{Inductive Coupling Device (ICD)}

In the late 1820 s, Michael Faraday discovered that voltage is induced through a conductor moving through a magnetic field, or a magnetic field moving around a conductor. His law states that Voltage ( $V$ induced) is equal to the wire's number $(N)$ of turns times magnetic flux over current $(h)$ or:

$$
V=N \frac{\Phi}{I}
$$

The School of Physics in Sydney, Australia, states in their "Transformers" multimedia archive that Faraday's principle is followed if two coils are inductively coupled, converting ac power at a certain voltage level to ac power at a different level but same frequency; if there is a current change in one coil an ElectroMagnetic Field (EMF) is induced in other [46]. A high voltage pulse transformer was preliminary considered for the ICD to allow an interface between the low voltage devices and the $4.16 \mathrm{kV}$ power line, but lab tests showed that implementing the same transformer's concept to a less 
expensive iron core with a AWG 32 wire can work as the ICD induce the necessary signal for the coupling system to send/receive data through the power line. As shown in Figure 3.8 , the high voltage cable passes through an iron core with an AWG 32 cable with 200 turns. From transformer's design we get the induction ratio ( $r$ :

$$
r=\frac{V_{s}}{V_{f}}=\frac{N_{s}}{N_{f}}=\frac{200_{s}}{1_{p}}=200
$$

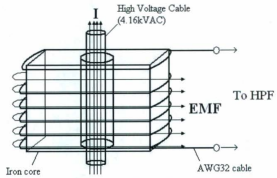

Figare 3.8. Inductive Coupling Device Diagram

The reason for the "high voltage cable pass through" design insteud of spiraling it around the core is to model a non invasive ICD that will avoid disconnecting the power cable from its original installation, same principle as an inductive clamp. 
As a counter measure to prevent unwanted signals passing to and from the inductive coupling stage, an inverted HPF was connected to the PLC modem input and ICD input as seen in Figure 3.9, therefore guarantying uncontaminated communication between the devices. Please refer to Appendix E for full DAST schematic.
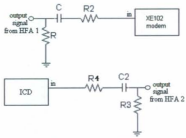

Figare 3.9. Inverted HPF

\subsection{COMMUNICATION SYSTEM PROTOTYPES}

Figure 3.10 shows the prototypes of above communication system; the DAST (left) has the wireless LaridTech AC4790 transceiver on top, PLC Netgear XE102 modem on the bottom left comer, and the ICD on the top right; the MPCBR has the wireless transceiver on top, PLC modem on the bottom right corner, the ICD on the top right, and a small cooling fan for heat removal purposes. 


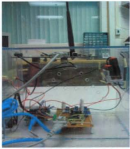

DAST

Data-Acquisition System Transmittes

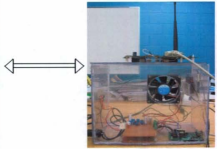

MPCBR

Main Power Control Building Receiver

Figare 3.10, Commanicatien System Protatypes

\subsubsection{Graphic User Interface (GUI)}

A Visual Basic GUI is designed to be operated by the user for data control and communication path supervision between the DAST and MPBCR. As seen from Figure 3.11 the user is capable to manually start/stop all transmissions or enable/disable each communication link individually, but there is an automatic background process which constantly seans for new incoming data, evaluates which comm. system was used, displays incoming data in real time, and transmits the acknowledgment signal through the same comm. link.

Since the DAST PLC modem is directly connected to the XPORT Serial-to-Ethernet adaptor, a TCP/P virtual port is necessary for Power Line Communications while the computer serial port is used for wireless transmissions. Appendix $\mathrm{C}$ contains the Visual Basic source code. 


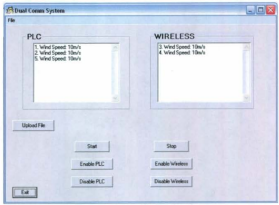

Figure 3.11. Graphic User Interface

For lab experimentation it is necessary to setup the DAST and MPCBR to an emulated 4.16kVAC power line so both ICD systems have to be coupled to a high voltage cable connected to four 120V-2kVAC transformers in series, two for each side. The GUI must be earefully supervised to display which communication medium was used for data transmission/reception and broadcast the acknowledgment signal through the same medium.

Going through above engineering design we have the PIC16F873A following its own algorithm which not only emulates receiving wind turbines parameters but will also controls the high frequency buffer configuration; the buffers art connected to the XPORT module and the MAX232, this last communicates with the AC4790 transceiver; the XPORT transmits the data to the XE102 modem which sends the data through an HPF, 
HFA, an inverted HPF, and finally through the ICD which induces the signal into the 4.16kVAC cable. To close the communication loop the GUI will use the MPCBR to acknowledge transmission as soon as it receives and displays wind turbine parameter data. Now the designed Communication System for the Remote Hybrid Power System in Ramea, NL is ready for experimental testing. Next chapter provides some experimental results. 


\section{CHAPTER 4. EXPERIMENTAL RESULTS}

The microcontroller's algorithm, transmission synchronization, induced data reconstruction, acknowledgment of new acquired data and sub-stages were tested in sequence in order to isolate and resolve possible difficulties with the DAST, MPCBR, and GUL. Challenging conundrums like transmission synchronization with the high frequency buffers command controls as well as signal coupling, filtering and amplification were deeply examined in order to achieve optimal results.

Experimental testing results confimed a successful DAS - MPCB communication as expected. Studies of these outcomes in addition to prototypes' cost analysis are documented as such:

- After testing numerous versions of the microcontroller's algorithm to solve synchronization difficulties with PLC-Wireless transmissions, it was necessary to first configure the microcontroller's USART and delay the primary transmission for 8 s to let the XPORT module initialize, as well as creating a sub-routine that decontaminates the Rx USART buffer before transmitting through wireless as scen in Figure 4.1. Full source code can be found in Appendix B. 


$$
\begin{aligned}
& \text { USART init(57600); } \quad / / \text { initialize USART module } \\
& \text { PORTB }=0 ; \quad \text { // Initialise PORT } \\
& \text { TRISB }=0 \text {; } \quad \text { // Configure PORTB as output } \\
& v=1 \text { : } \\
& \text { Delay ms(8000); } \\
& / / \text { validate send / receive data } \\
& \text { /Delay of } 8 \text { s to let XPORT initialice }
\end{aligned}
$$

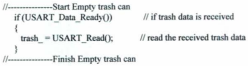

\section{Figure 4.1. Mierocontroller's Algorithen XPORT initialization + Baffer Decontamisation}

Laboratory tests determined that with above sub-routines the DAST can successfully communicate with the MPCBR and record data on a terminal computer via Ethemet without the loss of characters. Wireless and PLC signals had no instability and satisfactory transmission synchronization.

- As shown in Figure 4.2 , the high pass filter, high frequency amplifier, and the 4.16kVAC induetive coupling overall performance is acceptable for an ideal PLC communication. The Inductive Coupling Device transfers the high (Data) and low (60Hz power AC voltage at lower scale) frequency signals to the active high pass filter (HPF+HFA), $60 \mathrm{~Hz}$ sine wave is discriminated and only the data signal is amplified, then processed by the PLC modem, converted to TCP/P and last the parameter is displayed on the GUI. 


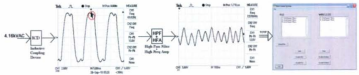

Figure 4.2. ICD \& HPF+HFA Signal

Transmission rate analysis under laboratory conditions shows that it can reach up to $1 \mathrm{Mb} / 20 \mathrm{~s}$ which meets the necessary scan rate requirement predetermined by wind turbine parameters on Table 2.1.

\subsection{COST - BENEFIT ASSESSMENT}

Taking into consideration what is mentioned in Chapter 1.2, paragraph 4 about not using low cost transceivers with a $2.4 \mathrm{GHz}$ transmission which is vulnerable to atmospheric attenuation, plus Newfoundland Hydro's fiber optic initial expense of CANS19,380.00 mentioned in Chapter 2.1; comparing it to what is shown in Table 4.1, a total hardware cost of CANS443.60 can initially satisfy the low budget cost-effective goal of the project.

Table 4.1. Hardware Cost

\begin{tabular}{|c|c|}
\hline Unit & Prize (SCAN) \\
\hline AC4790 & $\$ 62 . \$(\times 2)$ \\
\hline XE102 & $\$ 99.00(x 2)$ \\
\hline PICI6F873A & $\$ 400$ \\
\hline
\end{tabular}




\begin{tabular}{|c|c|}
\hline Unit & Price (SCAN) \\
\hline MAX232 & $\$ 0.50$ \\
\hline \$N74ABT125 & $\$ 0.90$ \\
\hline LM6171 & $\$ 2.80(\times 4)$ \\
\hline ICD & $\$ 2.00(\times 2)$ \\
\hline Miscellaneous & $\$ 100.00$ \\
\hline TOTAL. & $\$ 443.60$ \\
\hline
\end{tabular}

Considering that first prototype expense costs are always higher than the next ones, these modules can become even more economically attractive by reducing manufacturing expenditures if the DAST \& MPCBR are to be conceived as mass production products for different kinds of hybrid power systems, a very convenient aspect for power companies.

\subsubsection{Benefits}

There are fundamental benefits which determine the feasibility, advantage, and purpose of this project such as:

- Establishing a new and efficient approach to supervise wind turbine performance without compromising existing hybrid power system infrastructure.

- Reducing expenses by adding a second purpose to existing power cabling currently installed. 
- Minimizing communication failures attributable to hazardous weather conditions by establishing a redundant PLC-Wireless transmission.

- Limiting onsite travel to a minimum.

- A new incentive for engineers to innovate new practical products for current \& future generation of hybrid power systems.

- Possibility for a new market in the hybrid power communication system industry.

Taking into account the benefits that this communication system provides, it creates a new innovative approach to today's hybrid power systems market. 


\section{CHAPTER 5: CONCLUSIONS AND RECOMMENDATIONS}

The design of a Communication System for the Remote Hybrid Power System in Ramea, NL was not only challenging but insightful, studying the different types of hybrid power systems and their communication technologies provided us with a preliminary design that later on was engineered into an unconventional approach to communicate the different power systems. Hybrid communication for hybrid power systems combines the advantages of two different technologies working as one. Insights on these advantages are described below:

- The usefulness of implementing a half duplex transmission agreement with PLC and RF technologies combined is to assure the redundancy necessary for a constant and stable communication. A trustworthy remote transmission opens the possibility for automated systems to become more independent. Currently at Ramea the remote control is limited to a collective Enable/Disable of all wind turbines but future enhancements in wind turbine control's robustness will become possible with constant remote communication regardless of present weather conditions.

- Advantages like minimizing constant weather limitations will provide technicians with a reliable communication system for potential upgrades not only in remote supervision and control but faster technical response time on extraordinary circumstances like wind turbines malfunction, power eabling detachment, and data errot transmissions. 
- Implementing PLC modems and low RF transceivers to our system is not only an economically feasible approach to hardware communication expenses but can also reduce budget spending without allocating dedicated mediums to remote communication systems. Preserving Ramea's current power infrastructure will minimize system's downtime installation processes.

- Wireless enhancements to remote transmissions in addition to include extra tasks to existing power cabling with PLC will limit onsite travel to a minimum, therefore reducing fuel consumption, ground transportation maintenance, and traffic misfortunes.

- The Data Acquisition System Transmitter (DAST) was designed with the purpose of emulating the compilation of wind turbine parameter readings and resourcefully but yet efficiently transmit the data with low budget expenditure.

- Using a Serial-to-Ethernet XPORT adaptor allowed the microcontroller's TTL signal adaptation to TCP/IP corresponding to XE102 PLC modem's Ethernet protocol compatibility.

- A high frequency buffer arrangenent was implemented for the DAST as a matter to synchronize two communication technologies attached to a single data nequisition system. The master control for the buffer arrangement was suecessfully programmed 
in the mierocontroller which its inverse TIL outputs of pins $22 \& 23$ dictates which transmission is suppressed while enabling the other at the same time.

- The synchronization algorithm implemented to DAST's master transmission control was not only designed to be fully automatic but simple enough to be a recursive function with the limited amount of memory available in the microcontroller.

- Calibrating high pass filters and amplifiers for the inductive coupling stage was an overwhelming assignment with remarkable results that allowed the iron core induction device to send and/or receive suitable quality data. The retrieved signal was reconstructed with enough rigor to be duplicated in the Main Power Control Building Receiver (MPCBR) employing an equivalent circuitry.

- XE102 PLC modems where essential not only for data transmission through power lines but adding a special feature to the MPCBR, remote supervision anywhere in the Local Area Network. With proper routing network configuration the MPCBR data could be retrieved any where throughout the Worldwide Web.

- The Graphic User Interface (GUT) was designed to remotely recognize which communication method is currently been used for transmission, monitor and display the wind turbines parameters in real time as well as having user friendly features for communication control. 
- Matters like weather insulation, overheating protection, and power overloads must be taken into consideration for future upgrades to the prototypes with the purpose of avoiding environmental, structural and personal hazards, otherwise the system can become a mayor safety risk to the infrastructure.

\subsection{FUTURE WORK}

Various recommendations are reported in this thesis for future improvement of the "Communication System For The Remote Hybrid Power System In Ramea Newfoundland" in order to adjust the prototypes to multiple bybrid power system infrastructure configurations:

- A battery backup system and power management algorithms must be designed to take advantage of a semi-independent feature like having a constant communication in case the power system is switched off for maintenance or cabling detachment from the main power network. For future references, on Table 4.2 below you will find the theoretical load consumption of each DAST device in order to maintain a wireless connection with the MPCBR:

Table 4.2. Load Consumption

\begin{tabular}{|c|c|}
\hline Component & \\
\hline AC4790 & $65 \mathrm{~mA}$ \\
\hline PIC16F873A & $250 \mathrm{~mA}$ \\
\hline MAX232 & $5 \mathrm{~mA}$ \\
\hline SN74ABT125 & $64 \mathrm{~mA}$ \\
\hline Total Power Consumption: & $2.12 \mathrm{~W}$ \\
\hline
\end{tabular}


- Implementing a transformer bypass will eliminate the PLC constraint and transmit signal even if the DAST is connected before a main power transformer. An optical approsch might be the solution to overcome this limitation, a low budget laser point at one side of the transformer can be modified to be used as a transmitter while a lightreceiving device or diode is attached to the other side of the transformer, and with filters, amplifiers and ICDs, the signal can be re-adapted for PLC transmission. The light transmitter and receiver must be encapsulated on a dark/black cylindrical non metal tube to avoid losing data packages or transmission errors.

- Future studies on how to interface the prototypes with hybrid power system's centralized supervisory controller to analyze compatibility challenges.

- Implementation of a compatible eneryption algorithm for the DAST and GUI to avoid a potential system cracking or data theft.

- Include a Log file for the GUI which automatically records date, time, source, communication path, and type of incoming data.

- Improve GUI to display all information from the Log file.

- Secure Routing configuration for data recording through the Internet.

- Modification to the prototypes' encapsulation boxes for easier transportation, smallet dimensions, and easier user friendly installation features. 


\section{BIBLIOGRAPHY AND REFERENCES}

[1] T. Ackerman, "Wind Power in Power Systems". Chichester, West Sussex UK: John Wiley \& Sons Lt, 2005, pp. 299 - 316. [Online], Available: http//books, soogle cabooks?id-17MDGCiOgiMCEprinteec-fontcovertivinoncpag edcq \&f false

[2] Meridian Energy (2010, Jan 11). -The Ross Lsland Wind Energy-SVage I Project" [Online], Available:

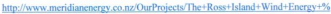
E2\%80\%93+Stage+1+Project htm

[3] S. Bennett, "Ross Island Wind Energy - Stage 1 Project, Building the World's Southern Most Wind Farm", project update presented at the New Zealand Wind Energy Conference, Mar 2010. [Online]. Available:

htip:/windenergy, otg nzidocumentsiconferencelowsbennett,pdf

[4] Renewable Energy Alaska Project (2010, Nov 15). "Hybrid Power Systems and Integration". [Online]. Available:

htip:/lalaskarenewableenergy org/wp-content/uplosds_201000/Hybrid-powersystems-ind-integration-111010.ndf 
[5] Renewable Energy Alaska Project (2010, Nov 15). "2010 Alaska Wind Projeet Updates". [Online]. Available:

http://alaskurenewablecnergy org/wp-content/uploads/201009/Annual-Wind-

Workiny-Group-Narratives,pdf

[6] National Renewable Energy Laboratory (2010, Feb 06). "US Virgin Island Energy Workshop". [Online]. Available:

hitp-/Wwwedinenergy,ory/pdfs/ce workshop 2010 gould elliott.pdf

[7] J. Zimmerman and C. Loone, "Session Three: Renewable Energies in the Remote Areas and the Top End", presented at the Regional Forum: Electrical Engineering in the Top End 2009 - IDC Technologies. [Online]. Available:

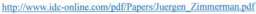

[8] D. Clarke (2011, Jan 20). "Wind farms in Western Australia", [Online], Available:

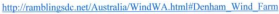

[9] P. Lundsager et al. (2010, Mar 13) "Isolated Systems with Wind Power Main Report". [Online]. Available:

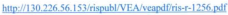


[10] J. Macgillivray, "Northem Wind Project Evolution- Tuktoyaktuk," in CanWEA 26th Annual Conference and Exhibition, 2010 \& Canadian Wind Energy Association.

[11] Cleveland Live (2009, Sep 05). "In Canada's tiny Tuktoyaktuk, they confront climate change up close as permafrost thaws". [Online]. Available: http:/fwww.cleveland com/world/index.sst/2009/09/in_eanadas tiny tuktoyaktuk_t h.him!

[12] CBC News (2010, Apr 10). "Tuktoyaktuk harnesses northern wind farm idea". News Report [Online]. Available: http:/www.cbe.ca/canada/north/story/2007/04/1(Wawt-wind.html

[13] CBC News (2010, Apr 10). "Tuktoyaktuk to get 4 wind turbines by 2011". News Report [Online]. Available:

heip:/Www ebc ca/canada/northistory/2000/06/02/tuk-wind-turbines, htonl

[14] T. M. Weis and A. Ilianca, "The Utility of Energy Storage to Improve the Economics of Wind-Diesel Power Plants in Canada", ScienceDirect, Renewable Energy 33, pp. 1544-1557, Oct. 2007. 
[15] PEI Energy Corporation (2010, Nov 21). "PEI Wind-Hydrogen Village". [Online]. Available: http://www windh2 cajprojectidesciphp

[16] B. Saulnier and R. Gagnon, -High Penetration No-Storage Wind Diesel study by Hydro Quebec in Quaqtaq, QC", in Wind Diesel Workshop, 2002 OHydro-Quebec Research Institute. [Online]. Available:

hettpi/hww docstoc com/does/6388181/Wind-Diesel-Hybrid-System

[17] Canadian Wind Energy Association (CANWEA) (2010, Jan 17). "Canada's current wind installed capacity table"; [Online]. Available:

bltpi/www. camwea.caufarmsindex e.php

[18] Canadian Wind Energy Association (CANWEA) (2010, Jan 17). "Canada's planned or under construction wind energy projects". [Online]. Available:

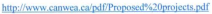

[19] Newfoundland Hydro (2009, Feb 25), "Ramea Wind-Hydrogen Diesel Project". [Online]. Available:

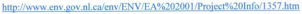


[20] Nalcor Energy (2010, Jul 03), "Ramea Report", [Oaline]. Available:

hettp: ihww nalcorenericy comipublications.asp

(Winter 2010 report of Ramea's Wind-Hydrogen-Diesel project done by Nalcor Energy (honp: / wwww.nalcorenergy_com/))

[21] Cirronet, Inc. (2009, Nov 09). "HN-210D User's Guide" [Online], Available: hetp:/ whw.cirtonet.comi07cicatalog/cirtunct/hn210 ue pdf

"Cirronet $\mathrm{HN}-210^{\prime}$ Datasheet.

[22] A. Pereira "Modular supervisory controller for hybrid power systems", Ph.D. dissertation, Dept. of Automation, Lyngby, Technical University of Denmark (DTU), Rise National Laboratory, Roskilde, 2000.

(Also available at http: 130.22656 .153 irisnuhl/VEA/veapdf $/$ is-1-1202.pdf)

[23] R. Sebostian, M. Castro, E. Sancristobal, F. Yeves, J. Peire, J. Quesada, "Approashing hybrid wind-diesel systems and Controller Area Network", IECON

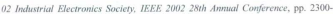
2305, Nov. 2002,

[24] H. Kirkham, A. R. Johnston, G. D. Allen, "Design Considerations For A Fiber Optic Communications Network For Power Systems", IEEE Transactions on Power Delivery, Vol. 9. No. 1, pp. 510-518, Jan. 1994. 
[25] Mary Bellis, About.com, Inventors (2010, Jan 22) "The birth of fiber optics". [Online], Available: hitp//inventors.about.com/lihnary/weckly/aa980407.htm

[26] Home Theater Accessories Resource (2010, Jan 22) "How Optical Cable Works". [Online]. Available:

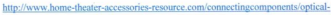
cable.html

[27] A. Akbulut, H. Gokhan Ill, F. Ari, "Design, Availability and Reliability Analysis on an Experimental Outdoor FSO/RF Communication System", Transpurent Optical Nenworks, 2005, Proceedings of 2005 7th International Conference, Vol.1, pp. 403406, Jul. 2005.

[28] Renesas Electronies Coorporation (2010, Apr 04). "Introduction to CAN". [Online]Available:

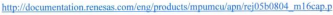
df

[29] Intel Corporation (2010, Jan 25) “Helping Define 802.11n and other Wireless LAN Standards", [Online], Available:

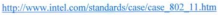


[30] Inter Corporation (2010, Jan 25) "How WIMAX works". [Online]. Available:

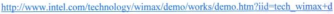
cmo

[31] Dr. J. Takei, Intel Corporation (2009, Jan 25). "Digital Wireless Communication Basies: Overview of basic concepts"'. [Online]. Available: hitr:/www.soi.wide.ad.ipichass/20070044/slidesiol

[32] D. D. Bois, Energy Business (2009, Jan 25), "Broadhand over Powerlines (BPL) in a NutsheII". [Online]. Available: http:lienergynriorities.comientries $2004 / 2$ broadband_over_1 phe

[33] Home Automation Directory (2009, Jan 25). "Home Automation", [Online]. Availabie: httpirithome-automation.orel

[34] NETGEAR (2009, Jan 25), "NETGEAR Powerline and Coax products". [Online]. Available: hitp:/ www netgear com/homeiproducts/powerline-and-coax/

[35] X10 (2009, Jan 25). "Transmission theory over X-10 signals". [Online]. Available: http:/Wwww.eurox 10.com/Content/X10SignalTheory him 
[36] Echelon Corporation (2009, Jan 25). "LonWorks Technology Overview". [Online]. Available:

hHp//www, echelon.comicommunitiesenergycontrol/developervillonworks

[37] Smart Labs Inc. (2009, Jan 25). "INSTEON Technology". [Online]. Available: httrillwwwinsteonnet/about-hoime.html

[38] L. Brackmann, ATICON Home Automation GmbH, "Power line applications with European Home Systems (EHS)", presented at the International Symposium on Powerline Communication and its Applications, Essen, Germany, 1997.

[39] KNK (2009, May 22). "KNX PL 110 Communication Media". [Online]. Available: hetp:/www.kns.ere/knx-standard/communication-media

[40] AeroComm, Inc. (2009, Sep 17). "AC4790 Transceiver datasheet" [Online].

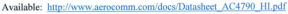

[41] J. F. Acevedo, M. T. Iqbal, "Communicatian System for the Remove Hybrid Power System in Ramea Newfoundland", Electrical and Computer Engineering (CCECE), 201023 rd Canadian Conference, pp. 1-4, May 2010. 
[42] J. F. Acevedo, M. T. Iqbal -Dual Communication System for Ramea's Remote Power System", in CanWEA 26th Annual Conference and Exhibition, 2010 o Canadian Wind Energy Association.

[43] Lantronix, Inc. (2009, Mar 15). "XPort Embedded Device Server" [Online]

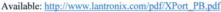

[44] V. Krishnan, "Transformer Bypass Circuit", Power Line Comminications and lis Applications, 2005 International Symposium, pp. 275-277, Apr. 2005.

[45] A. S. Sedra and K. C. Smith, "Microelectranic Circwits", fitth edition, New York, Oxford: Oxford University Press, 2004, pp. 64-122, 1084-1101.

[46] School of Physics, Sydney, Australia (2010, Jan 12). "Transformers", [Online]. Available:

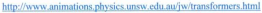

[47] U. Abdulwahid et al., "Development of a dynamic control comminication system for hybrid power systems", Renewable Power Generation, IET, Vol. 1 No. 1, pp. 70-80, Apr. 2007. 
[48] V. Chunduru and N. Subramanian, "Effects of Power Lines an Performance of Home Control System", Power Electronies, Drives and Energy Systems, 2006. PEDES '06. International Conference, pp. 1-6, December 2006.

[49] O. Bilal et al, Design of Broadband Coupling Circuits for Power line Communication", presented at the $7^{\text {th }}$ ISPLC Proceedings, 2004 


\begin{abstract}
APPENDIX A. RAMEA WIND-HYDROGEN-DIESEL PROJECT, RE.ALISTIC POINT COUNT FOR EMS GROUP - ST. JOHN'S
\end{abstract}




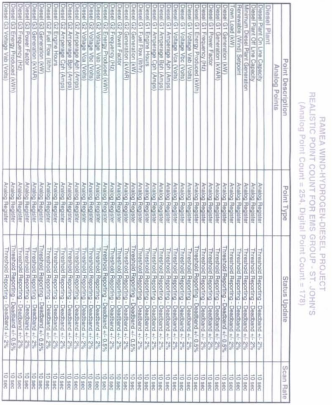




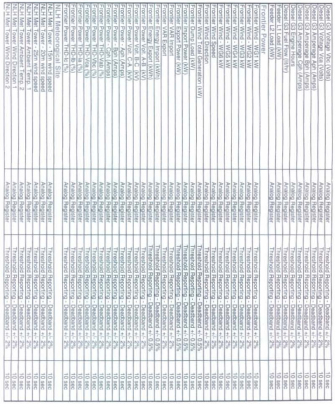




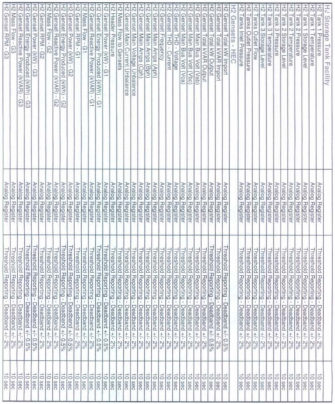




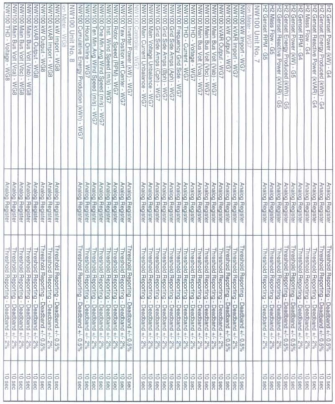




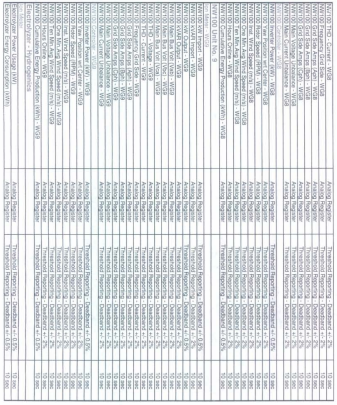




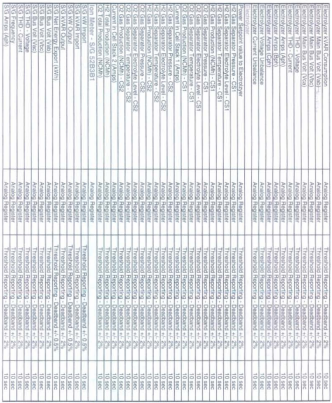




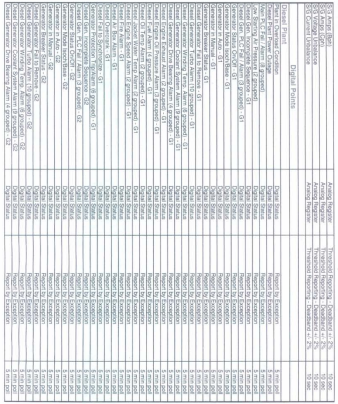




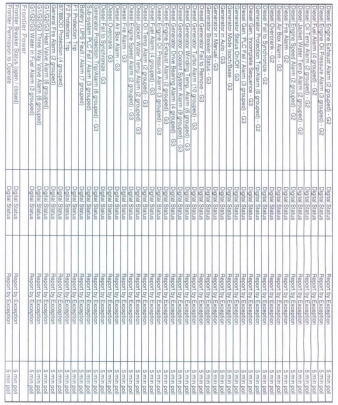




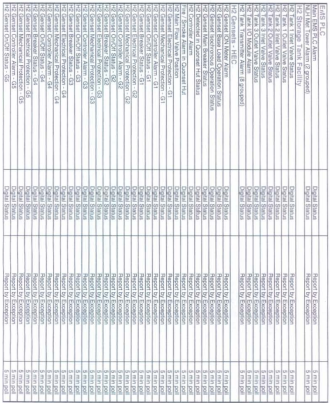




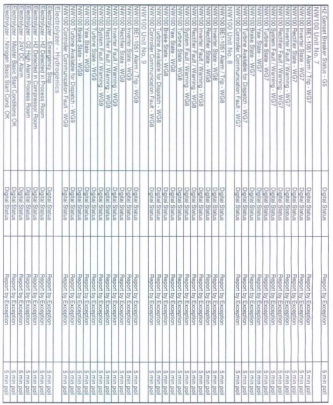




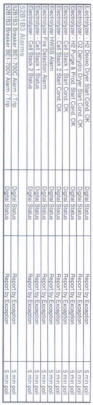


APPENDIX B. MICROCONTROLLER (DAS) SOURCE CODE 


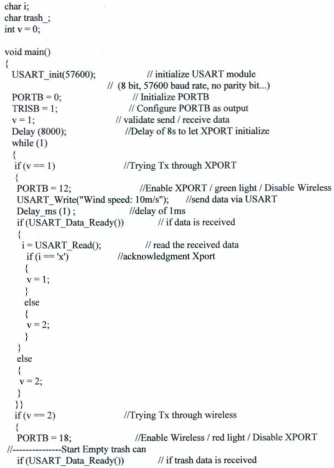




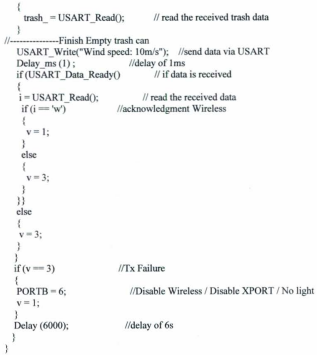


APPENDIX C. GRAPHIC USER INTERFACE SOURCE CODE 
Option Explicit

Dim xport_rx As String

Dim wireless rx As String.

Dim m As String

Dim n As String

Dim temp As Integer

Dim numfile As Integer

Dim numfile2 As Integer

Dim LineaDeTexto As String

Dim TodoElTexto As String

Dim modu As String

Private Sub StopCommand Click0)

Textl. Text $=m$

Text2. Text $=" *$

If MSComm 1 PortOpen = True Then

- MSComml PortOpen - False

Fnd If

If MSComm 3.PortOpen - True Then

- MSComm3.PortOpen - False

Find if

End Sub

Private Sub StartCommand Click0

' $\mathrm{m}=$ "e"

Textl. Text $=* *$

Text2. Text $=*+$

$\mathrm{m}=$ "ex"

$\mathrm{n}=" \mathrm{ew} "$

MSComm 1.PortOpen = True

MSConm3.PortOpen - True

Do

DoEvents

If MSComm 3 InBufferCount $>0$ Then xport $\mathrm{rx}=\mathrm{MSComm} 3$. Input

Text1. Text $=$ Text1. Text + xport $r x$

xport $\mathrm{rx}=$ " $\mathrm{w}$ "

If $m=" e x "$ Then

MSComm 3,Output $=$ xport $r x$

End If

" numfile $=$ numfile +1

- L.abel2.Caption = "XPORT: " + numfile

End If

If MSComml InBufferCount $>0$ Then

wireless $\mathrm{rx}=\mathrm{MSC}$ Comml.Input 


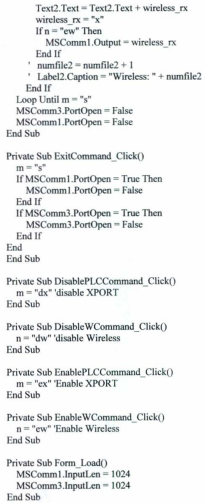


APPENDIX D. COMPONENTS' DATASHEETS USED FOR THIS PROJECT 
National

Fetruary sone

Semiconductor

LM6171

High Speed Low Power Low Distortion Voltage Feedback Amplifier

\section{General Description}

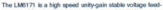

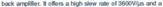

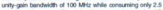

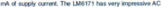
ane DC petomanse which in a graal lenebli ior high spoed

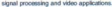

The s15V poner apeles illow for lage sigred swergs and

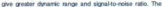

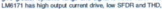

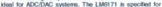

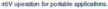

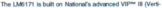
coly integrand PWP / complemereary beclar peocess

\section{Features}

Thrical Unine Chervise Notal

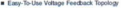

- Ven Hon Blew Pater sevovis

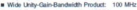

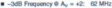

- Low Bumply Curent $2.5 \mathrm{ma}$

- Hohicurse nods

- Hoh Conenlerp Chart mas

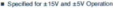

\section{Applications}

- Uhaneda Buadoat Byemem

- Une Drwers Swates

- Wies areilien

- NTSC, PAL- ard secuu Bysum

- Aoconacialter

- HOTV Nmilies

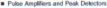

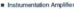

- Acter Plies

\section{Typical Performance Characteristics}

Cased Loop frequency heaponbess. Supply Volleip $\left(A_{n}=+1\right)$

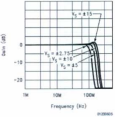

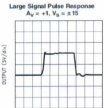

hat log initin 


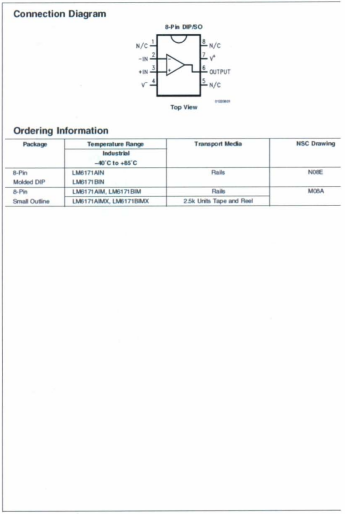




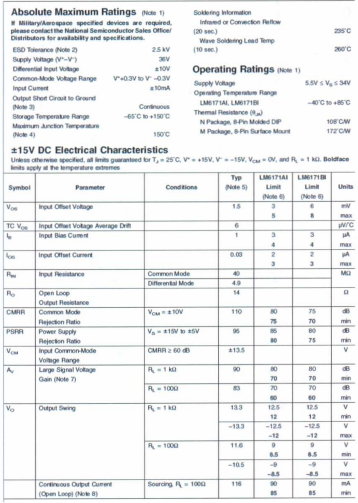




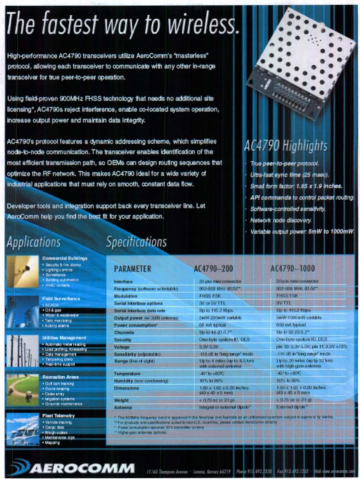




\section{Flexible RF Protocol}

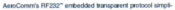
fies the ceM r rtequabon process by abowing lor dupin

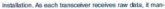

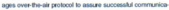
fon Header. dath packet length and Cros are not nesod.

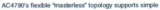
catb-mplacoment up b complex peerto-peer confounation:

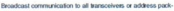

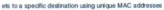
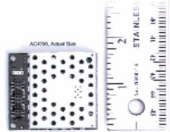
wirediod in each tranecohes

\section{Protocol Features}

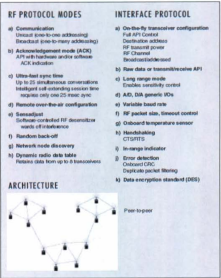

\section{Plocing Orders}

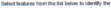

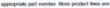

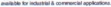

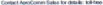

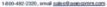

\section{PART HUMBERS}

\section{acarab-roes}

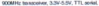

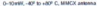

\section{Acurat- rega.}

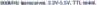

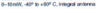

\section{AC4794-1400\%}

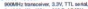

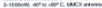

ecapatiot

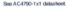




\section{SN54ABT125, SN74ABT125 QUADRUPLE BUS BUFFER GATES WITH 3-STATE OUTPUTS

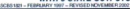

- Typical Veup (Outpot Grosmed Bounce) $51 \mathrm{~V}$ at $\mathrm{V}_{\mathrm{CeC}}=5 \mathrm{~V}, \mathrm{~T}_{\mathrm{A}}=25 \mathrm{C}$

- Migh-Drive Outsuse f-32-ma bat 64-ma bi

- Ln and Puwer-Up astale Support Hot Insertion
- Latch-Up Rerformance Eeteds $500 \mathrm{~mA}$ Pur Jroec standard JEse- 7

- Eso Preblection fromeds dfso 22

- 2000-V Human-Bedy Model (A II - h)

- 200-V Hachire Model (Ants-A)

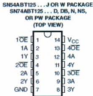

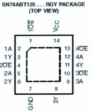

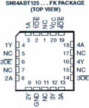

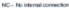

\section{descriptionfordering information}

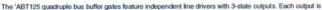

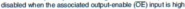

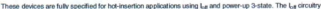

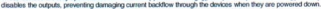

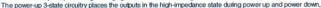
Which prenents diver contist.

To ensuve the high impedance etate during poes up or power down, OE shoud be tied to Vor Nough a piap

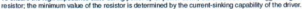

CADE FMT INFOAMHTION

\begin{tabular}{|c|c|c|c|c|}
\hline$T_{k}$ & \multicolumn{2}{|c|}{ PMCKACE! } & $\begin{array}{c}\text { ofberane } \\
\text { Futr muemen }\end{array}$ & 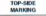 \\
\hline \multirow{7}{*}{-200 bo } & PDO - $A$ & That & seactiast & Bowew Lew \\
\hline & of $N$-ngi & Tree and net & 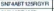 & ABili \\
\hline & \multirow{2}{*}{$5000-0$} & $\mathrm{Tat}$ & 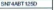 & \multirow{2}{*}{ Aertas } \\
\hline & & Tige arod inet & ME MEtrason & \\
\hline & $509-N 8$ & Zee ond wes & BNYLET QWSA & AETIS \\
\hline & $3800+$ ts & Kee and men & SWESET WoSph & A6t25 \\
\hline & Tainco- $F W$ & Few ind mel & sapcest oypwi & ates \\
\hline \multirow{3}{*}{-600 o 450} & CDAP-3 & use & swuscabitas & SWDaneitiks \\
\hline & $\mathrm{CH}-\mathrm{W}$ & Nos & SNus4ait tasen & SNBANOThEW \\
\hline & $\operatorname{LCCC}-F \bar{R}$ & nite & Dastaer ESK & Shbever bes $\mathrm{K}$ \\
\hline
\end{tabular}

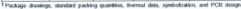

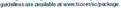

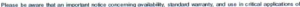

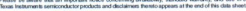

\section{1y. Texas INSTRUMENTS}

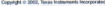
omanom 
SN54ABT125, SN74ABT125

QUADRUPLE BUS BUFFER GATES

WITH 3-STATE OUTPUTS

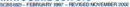

Fucrom tahis.

iesch tefley?

\begin{tabular}{|c|c|c|}
\hline \multicolumn{2}{|c|}{ Mavis } & \multirow{2}{*}{$\begin{array}{l}\text { क्याजन } \\
\text { \% }\end{array}$} \\
\hline T & A & \\
\hline $\mathrm{t}$ & "H & \# \\
\hline 1 & 1 & 1 \\
\hline$n$ & $x$ & $z$ \\
\hline
\end{tabular}

logic diagam (positive logic)
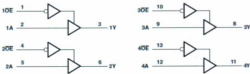

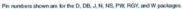

absolute maximum ratings over operating free-air temperalue range (unless otherwise noted)

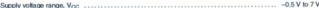
input votage manos. $v_{1}$ inee Nete i)

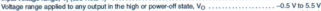

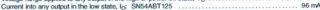

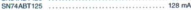

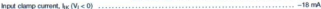

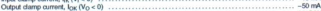

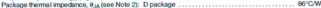

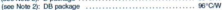

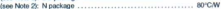

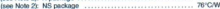

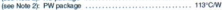

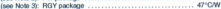

Storage timperahse range, Tito

-650 to 1500

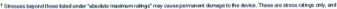

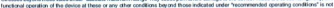

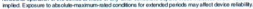

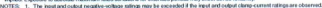

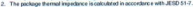

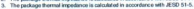

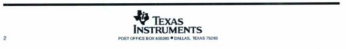




\section{LNIRONIX'}

\section{XPort ${ }^{m}$ Data Sheet}

\section{General Description}

The XPort' is the mest comper irtegrated sokition avalabile to anb-enable any device with a

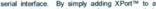
product deson. devoce mandacturers of ther design cycle by as much as BOSt and we uble to Clfer fithernes connectwity in recond $5 \mathrm{me}$

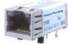

The xpert oflens the highest ievel of integration aralable in a device server. Wein a comped R.J45 package is a DSTeiEX 186 controlle. memery. $10 \% 100$ Ethernet tranceever, hgh-eseed serial por. stikis/diagneatic $\mathrm{EDE}$ and 3 propianmakie 10 pors in the space that is normaly consumed by a connector. the XPert provides a complete notarking interface.

To enabie access to a locial network or the intemet the XPort integrales a fully developed TCPMP retwaik stack and DS The XPort also indudes an embedided wob server ined to remokely conflgue montor or troubieshoot the intached devioe.
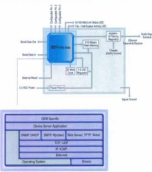

Where there's a roed for custom uner inlertaces and a dasire to ise common and fambiar tools, the XPort ean serve wet pages to a wht beowses. The XPort becomes a conduit betineen you and your device over the network of hernet.

The Whoussmbared conflguration sotwae. Devicethsibler, sircifles instalation and setup. The XPot can iso be set up bealy through is serial port or rencledy over a netwoik using Telnet of a web browser. Fish memory provides for mahtenance-bee nonvolatie storage of web pages, and slows fihre system sofhere upgrades

Ueng bur highy integated hardeare and soltwave plation, you wit add pretl to your botsom line by signifcanty reducing product development time. rink, and pold

\section{Key feratiares}

- Theonty ecmpleit irtegrated sulution in an Rues torn facker

- Conctile viegrabod sution.

- Entredalod web seiver

- Tornocmet Epernet - Aupo-fiensing

- SAele fied paven TCPYP probod wate and nebhesed agcicason tarmern

- Easy contouraion thraph a wob intertace

- Easy taskoninaicen of HTML web poges ard eentguration seteria

- Vheractive web pages trough the lase of Jive acplets

- Emal

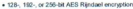
(Cpicinal]

- De inetred and obmplart

- Eranded coevatins lamperiare -40 is +15 Cnema reode

40 is +75 Chigh-perbormanca mode

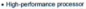

(12 Mips ad 4 a Mre. 22 vaps a ta Mier

- Netecat overtesd harillot by XPart

- Passecri piviestien

- Upgraile XPot L knwas over the networs

- 1 N power

- Sertatb-10/s00 Ehinet comenion

- wes soeband seral seeed 


\section{Hardware a Soltware Description}

The XPont is a complete soluton phardwars and sotware) for web-enating your bdgh devicen Paded into an Ruas conredor anewr thin your furmt this powerfy device keraer comes with a 1CEASE-TIO0EACE-TX Fremet connection. nelable and proven egerating system stored in flash meition, an eribedbed wob server, a fil TCPIP protocol atack, and standiuds based (AES: encryptisn

The XPent sohware tuns on a DSTris EX conbolver which has $256 \mathrm{~KB}$ of SRAM $16 \mathrm{~KB}$ of boat FOM and a MAC with integrated $10400 B A B E$ TX PAT The XPort communicates to the edge device hrough a 3 JV serial intertace and thee peneral. purpose progranmate 10 pins. 512 KB of flash memory is rotuded for storing frmware and neb pages. The XPort nue on $3.3 \mathrm{~V}$, and has a buth in votage superdiony diroul thit will trigoer a reset i

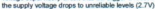

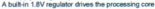
of the FX, comtidiet

An R.A5 Ethemet calle correcta drectly into an XPor F themet magnetion, talus LFDs and sfielbing are but in. The XPort was designed ac meet class B eminsiens kvels, which makes the eiectromecharical inkegation wery simple.

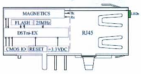

\section{Acal Interfince}

The spin PCE irenflace consists of $3.3 \mathrm{~V}$ CMOS Seriail in Oue. 3 Flow ConerdiAlandshakerpiO pine. teset inper $+33 \mathrm{~V}$ power, and sional ground. signal pins Dora in. Data Out and CPx are SV bierant
Tatie 1 + PCE istentace Signais

\begin{tabular}{|c|c|c|}
\hline mants & Fin & Thanar \\
\hline 00 & 1 & Drael Conent \\
\hline Nex & E. & 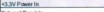 \\
\hline Fona ay & 3 & Otnef fenet is \\
\hline cuecir & 4 & Fearbeat \\
\hline Gatain & 3 & Downes: \\
\hline con & b & 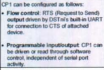 \\
\hline opt & $p$ & 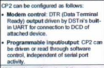 \\
\hline $\mathrm{cos}$ & p & 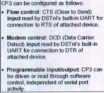 \\
\hline
\end{tabular}

Whemet Inter face

The 10100 Edemet magneics neteork stitus LFDs and RJas connecior are integrabed irto the XPon 1 .

Table 2 : Ethernet Interface Signals

\begin{tabular}{|c|c|c|c|}
\hline 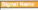 & 79 & 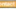 & 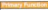 \\
\hline$\pi$ & QM & 9 & thasera bus + \\
\hline i2. & Ont & 2 & Tranent Dow - \\
\hline Erit & in & 3 & Heceve Dusa+ \\
\hline Eas: & in & 5 & Ahimeve Des - \\
\hline Wat beed & & 4 & Tampatal \\
\hline Mathed & & 5 & fermpoled \\
\hline Nost thed & & $z$ & Tramnabad \\
\hline Nat beat & & 8 & Irenivated \\
\hline DELD & & & Cleasin Ginned \\
\hline
\end{tabular}




\section{Pratecal siopport}

The XPort uses hemet Protocet (FP) for network. commuricabions and Tranemisaion Control Protocel (TCP) to ssevere that no dats is bet or duplicaled, and that everything sent amves ecrectly at the tarpet.

Other supponed protocols are lasted below:

- AFP uDP TCP, ncup Tehet TFTP, nubof. Drap HTIP, and siak for hetwos commaneders.

- TCP, UDP and Teher lar comectors b the sala pont.

- TrTpia temaves ipdides.

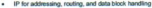
coer the reteres.

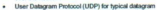

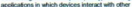
derdons whoit mantaning a point - bopont conreston.

+ For a cornctele dscassios of probod support see the XPert user manual

\section{LIRDS}

The device contains two bh coler LEDs balt hat funt of the XPoit comector. (Fee dinerwion drawhy for beston ?

\begin{tabular}{|c|c|c|c|}
\hline Farde & HEF & 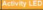 & 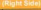 \\
\hline $25=$ & T & etgrat & Wertenty \\
\hline on & ne Lin & cot & ins Achey \\
\hline gonber & Dothes & Wnter & perf-Dester \\
\hline Orean & no Mept & Geren & haspest \\
\hline
\end{tabular}

\section{Recomamended PC Aosard Laveut}

The hole parem and mounteg dimensions for the XPort ais shown in the following drawing

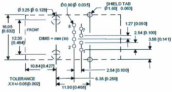

For preper heat dissipation, the PCB should have acproamately 1 square inch of copoer unached to the shivid tabs. The shiced tabs are an important source of heat sinking for the device.
DVmensians

The XPent drwernion we shown in the following drawing:
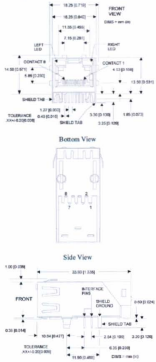

Wote PAOS and PROTEL design fies are incturted with the XPort development in 


\section{XPort Technical Data}

\begin{tabular}{|c|c|}
\hline contogon. & Deschination \\
\hline CFE. Mmory & 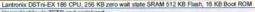 \\
\hline Finmere & 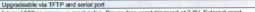 \\
\hline Feset Cirsa & 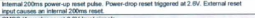 \\
\hline Sets intertace & 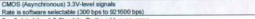 \\
\hline Betoline Femsh & 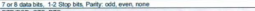 \\
\hline Mothe Contol & DIFINCD, CTS RTS \\
\hline Fon Conind & 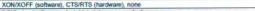 \\
\hline Foerannchis ing & 390 pris inotheye seloctociel cink or souce ind max \\
\hline Neves intertre & 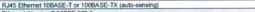 \\
\hline Compoebiny & Etemet Vesor 2 outelesas? \\
\hline Anovobs Suponed & 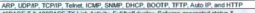 \\
\hline LDe & 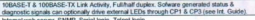 \\
\hline Mvoretinent. & 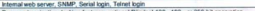 \\
\hline Secietly & 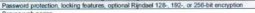 \\
\hline inkerwa Whab Server & 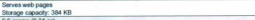 \\
\hline Whal & fregans pas or \\
\hline Moterial & Metal shell thermosiante cirse \\
\hline Temperian & 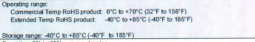 \\
\hline Fetabe Humichy. & 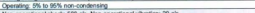 \\
\hline Shodvinaion & 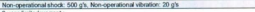 \\
\hline Whenes & 2-reat buted watring \\
\hline incbides tholtware & 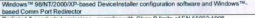 \\
\hline EMi Conslanon & 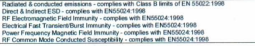 \\
\hline
\end{tabular}


APPENDIX E. DATA ACQUISITION SYSTEM TRANSMITTER SCHEMATIC 


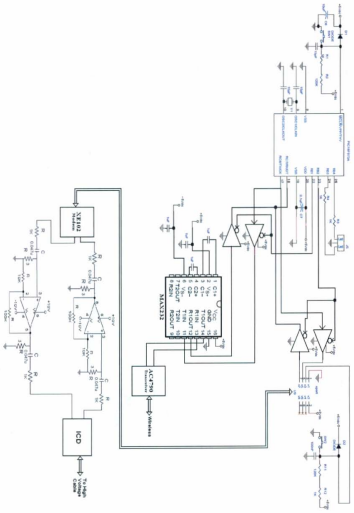





